
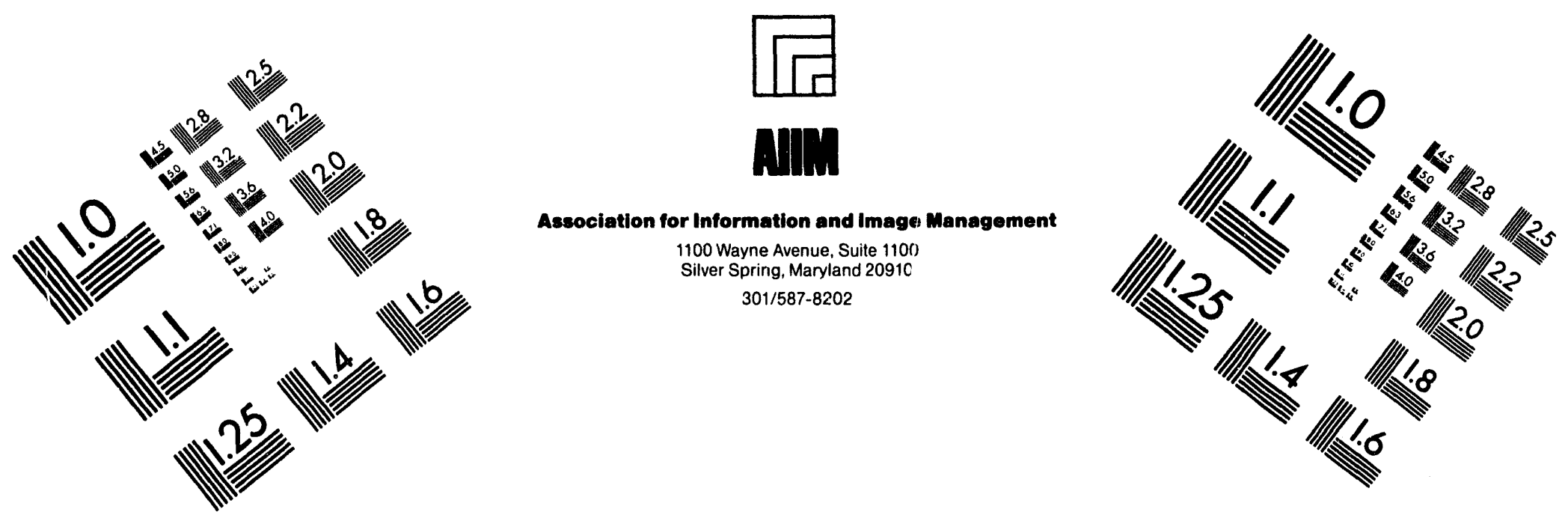

Centimeter

|m Inches
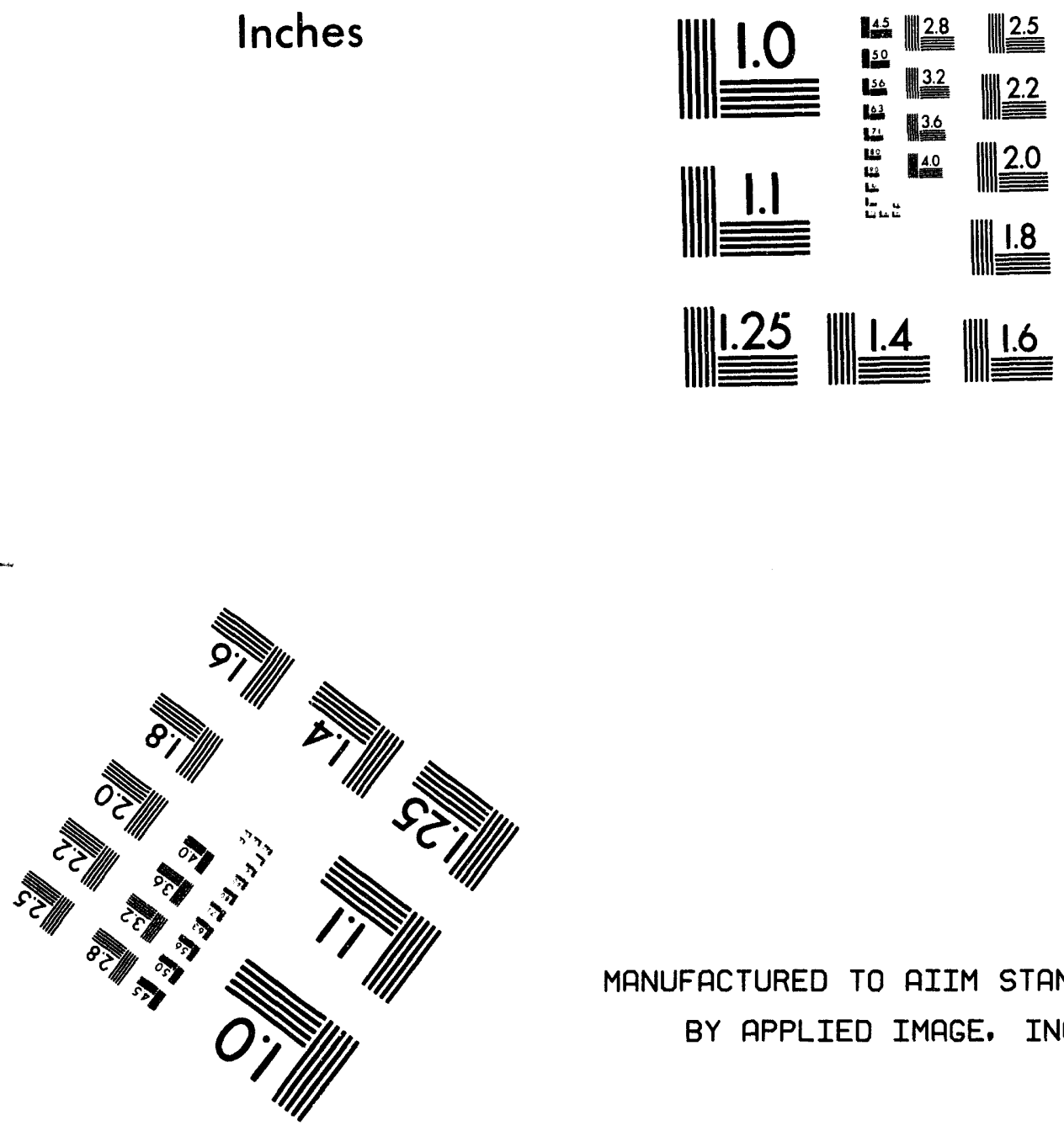

MANUFACTURED TO AIIM STANDARDS BY APPLIED IMAGE, INC.

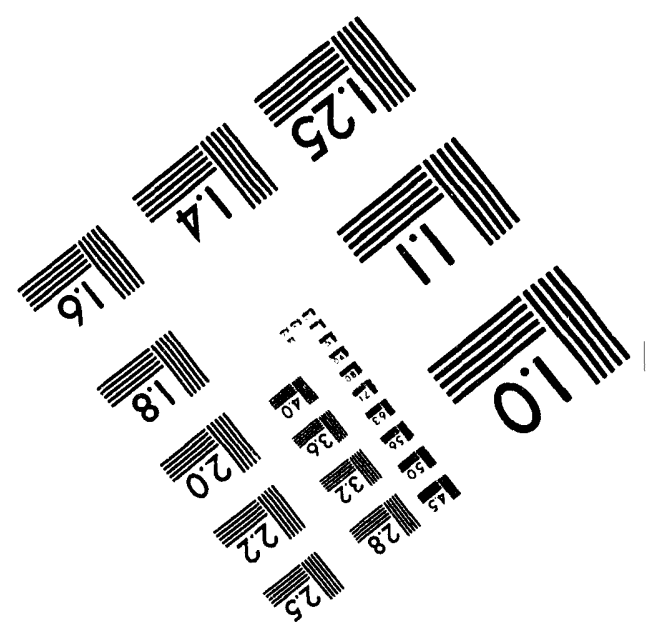



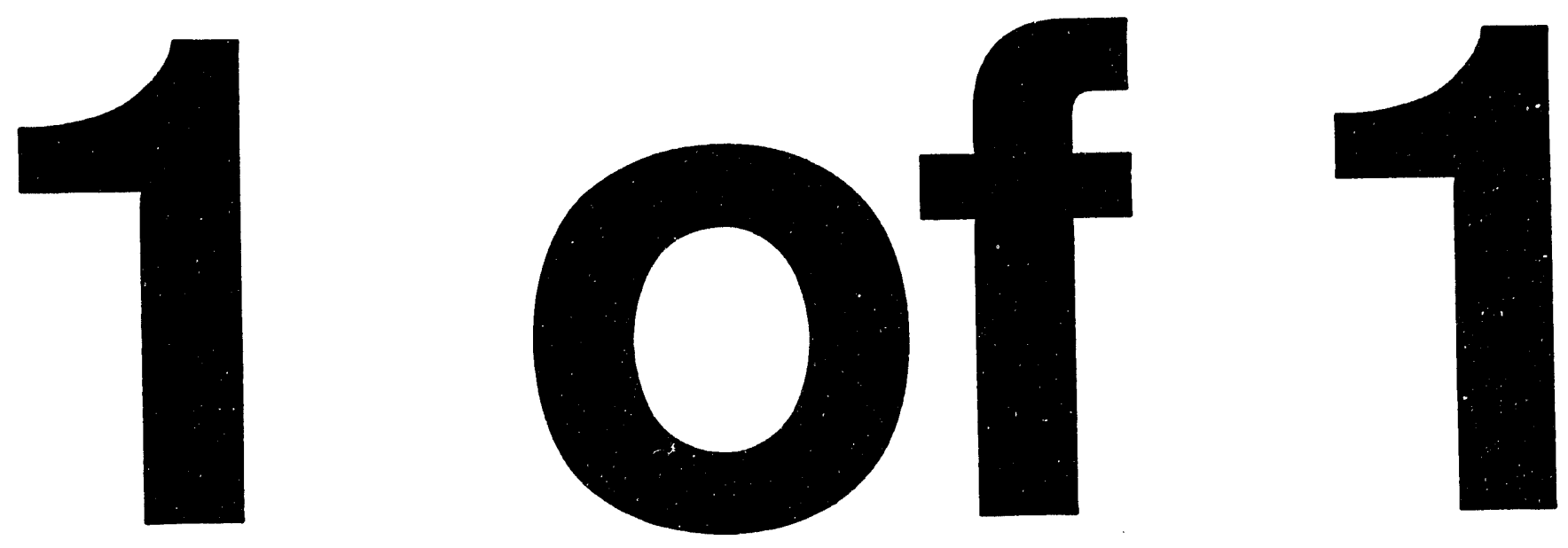


\title{
Digital Conversion of INEL Archeological Data using ARCIINFO and Oracle
}

\author{
Randy D. Lee \\ Julie Brizzee \\ Luke White
}

Published 11/4/93

\section{Idaho National Engineering Laboratory EG\&G Idaho, Inc. Idaho Falls, Idaho 83415}

Prepared for the

U.S. Department of Energy

Office of Energy Research

Under DOE Operations Field Office, Idaho

Contract DE-AC07-761D01570

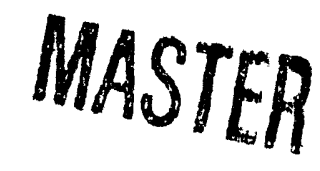

CHMmBUTION OF THIS DOCUMENT IS UIMLMITE 


\section{ABSTRACT}

This report documents the procedures used to convert archeological data for the INEL to digital format, lists the equipment used, and explains the verification and validation steps taken to check data entry. It also details the production of an engineered interface between ARC/INFO and Oracle. 


\section{CONTENTS}

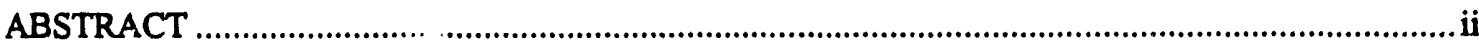

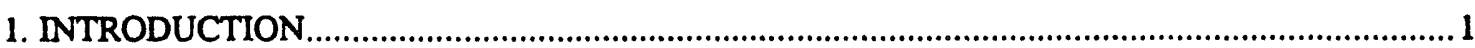

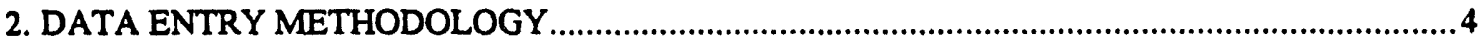

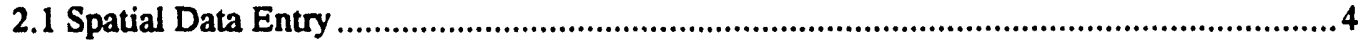

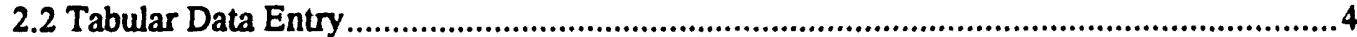

3. DATA VALIDATION AND VERIFICATION

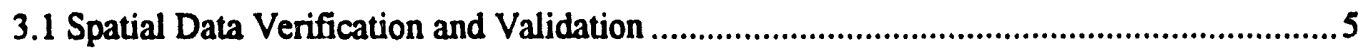

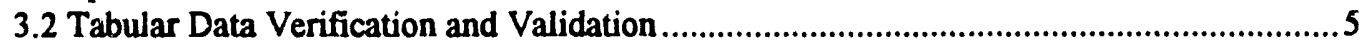

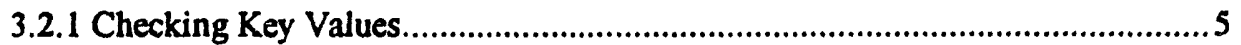

3.2.2 Quality-Assuring Key Entry for Oracle ..........................................................6

4. ENGINEERED INTERFACE BETWEEN ARC/NFO AND ORACLE ...................................

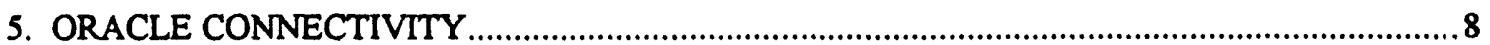

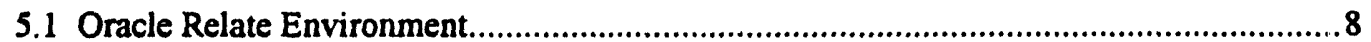

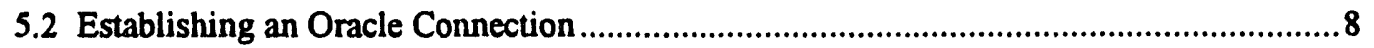

5.3 DBMSCURSOR / DBMSEXECUTE Arc Commands................................................

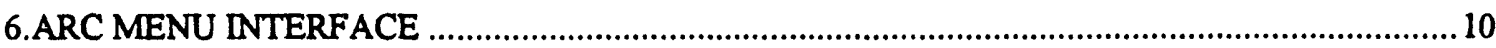

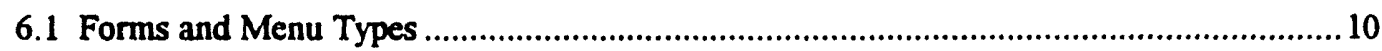

APPENDIX A A

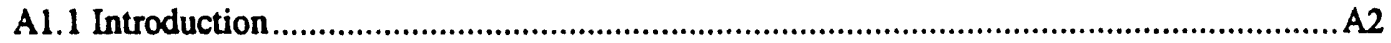

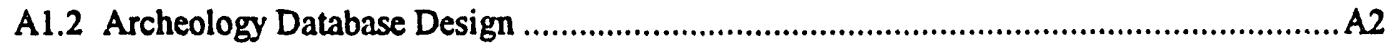

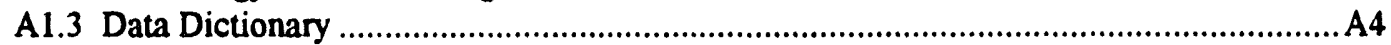

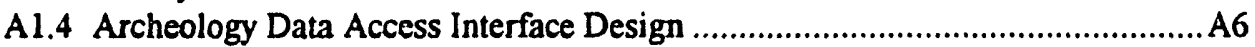

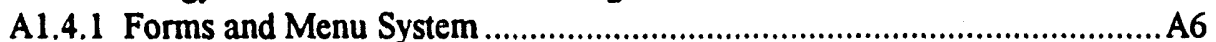

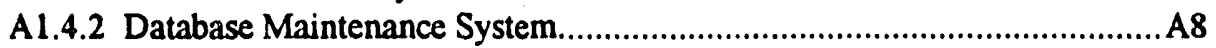

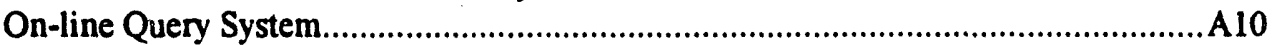

\section{Figures}

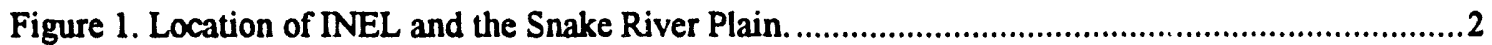

Figure 2. Cultural Resources on the INEL

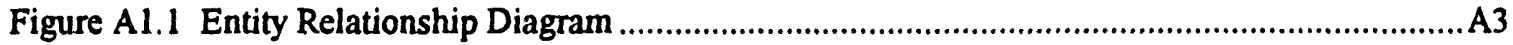

Figure A1.2 Archeology Data Maintenance Process Flow Diagram ................................................... 7 


\section{Digital Conversion of INEL Archeological Data using ARC/INFO and Oracle}

\section{INTRODUCTION}

For thousands of years, the sagebrush steppe of the northeastern Snake River Plain provided important resources along its seasonal migration routes to the aboriginal hunter-gatherer populations. As the principal land manager of the Idaho National Engineering Laboratory (INEL), the Idaho Operation Office of the U.S. Department of Energy (DOE-ID) manages a very large portion of this region and is responsible, under various federal statues, for stewardship of many archeological sites, or cultural resources, that can provide clues as to the nature of aboriginal prehistoric utilization (see Figure 1). Ongoing efforts to inventory all cultural resources on the INEL have resulted in the recording of more than 1400 resources (Figure 2) in the past decade. In the past, information gathered from these resources has been archived and managed in hard-copy paper format (i.e. topographic maps, multi-page site recording forms, hand tallied data tables). Recently these data have been converted to digital format to isolate spatial distribution patterning of different resource types for purposes of predictive modeling and to provide a more consolidated approach to overall management.

The data management system chosen is a combination of the Geographic Information System (GIS) ARC/INFO and the data base Oracle. The data were converted to digital format in two steps: digitization of the spatial data and key entry of the tabular data. After the data were entered several validation steps were taken to verify the accuracy of both the spatial and the tabular data.

Along with entering the data into the database management system, an engineered interface between ARC/INFO and Oracle was produced that allows the archenlogists to query and update the data interactively. The system has been engineered to support multi-limesional data querying and data maintenance.

This report explains the process used to enter the data into the system, the data quality procedures used to verify the data entry, and details the engineered interface between ARC/NFO and Oracle that was designed and implemented at the INEL. 


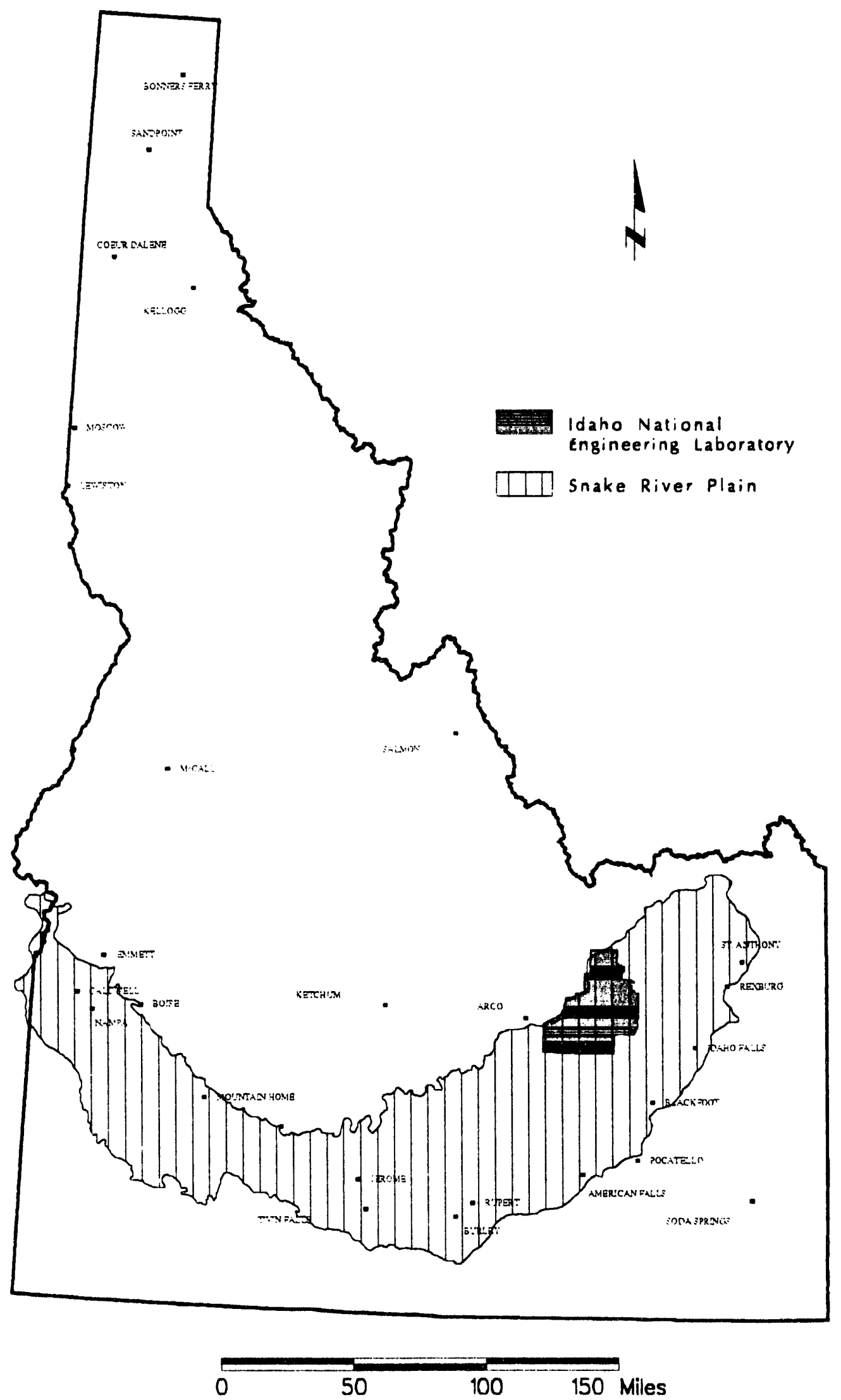

Figure 1. Location of INEL and the Snake River Plain. 


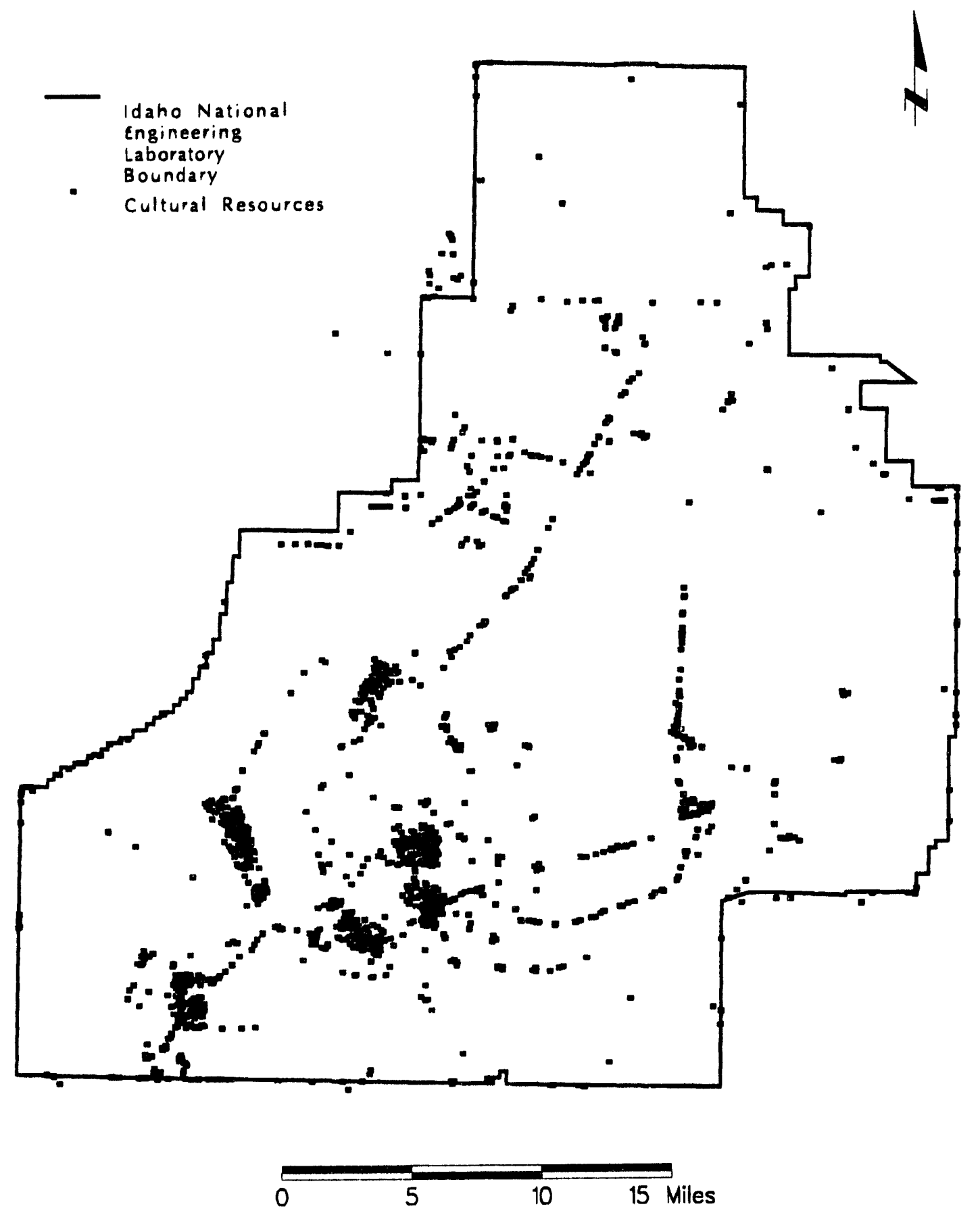

Figure 2. Cultrual Resources on the INEL. 


\section{DATA ENTRY METHODOLOGY}

Two different types of data were entered into the database management system using two separate methods. First the spatial data were entered with a digitizing board and second, the tabular data were entered using a custom designed Oracle form. This section describes these processes in more detail.

\subsection{Spatial Data Entry}

The spatial data recorded on paper USGS Quadrangle maps, were entered into the ARC/INFO system using a Kurta digitizing board. First, the maps were secured to the board with tape and covered with a sheet of mylar. Next, using the command COORDINATE with the arguments <digitizer \{cover\} \{affine\}>, where the \{cover\} was GRID_UTM (a polygon coverage of the outlines of the USGS Quadrangles for the INEL), the four corners of the paper map were registered to the four TIC marks that corresponded on the \{cover\} in the computer. Once the comers were registered, a RMS error was calculated by ARC/INFO and recorded for documentation purposes. An explanation of RMS error as well as the results for the digitizing session can be found in the section 3.2.

With the paper map properly registered to the $\{$ cover $\}$ in the computer, the sites that were defined by polygons, or as having area, were digitized and marked on the mylar with a grease pencil to avoid multiple entries of the same site. After all the polygons were digitized for the first paper map, the \{cover\} was saved from GRID_UTM to ARCH_POLY (a polygon coverage) and all subsequent digitizing of the polygon features was done on this coverage. After digitizing all the polygons on each map and before the grease pencil marks were erased, the site numbers (Site_num) for each point on the paper maps were read off by one GIS analyst and entered into the Info Attribute Table on the keyboard by another analyst. Once the Site_num was entered for each site, the person at the keyboard checked the grease pencil marks on the mylar to ensure that all sites had been digitized.

While many of the archeological resources on the INEL are defined by an area (sites), there are also resources which consist of one point on the ground (isolates). The two types of data, point and polygon, posed a problem for ARC/NFO since there is no way the program can distinguish between a label point for a single point feature and a label point for a polygon feature. To resolve this problem, two separate coverages were produced, ARCH_POLY and ARCH_PNT. The process described above for digitizing the polygon features was used to digitize the point features which were then saved to ARCH_PNT. Along with the point labels for each of the sites that were defined by a single point on ARCH_PNT, a label was added for recording the features from ARCH_POLY. Without these label points, there was no way to record all the attribute data for all the sites on one \{cover\}. All database queries can be performed using ARCH_PNT except area calculations. Area can only be calculated using ARCH_POLY.

\subsection{Tabular Data Entry}

The tabular data for each resource were recorded on sheets of graph paper with a site number Site_num in the first column followed by other relevant data. Site_num is the field that was recorded in both the Info table and the Oracle table and was used to link the two data sets. The data was entered via a custom data entry form which was produced using Oracle Forms 3.0. The form contained enumerated lists (pick lists) for data that appeared on the sheets repeatedly. The lists reduced the number of keystrokes 
required to enter the data and thus reduced the opportunity for error due to typing. 


\section{DATA VALIDATION AND VERIFICATION}

Data verification was performed in three levels. First the digitizing was checked for accuracy using a randomly generated subset of the total 32 Quadrangles (approx. 12\%) as overlay maps. Next the key values were checked between the two data systems to verify that no orphans were left in either database. Finally, a random number generator was used to select a small (5\%) subset of the Oracle data for subsequent comparison of the original records. This section details the data verification procedures in detail and lists the quantified results of each.

\subsection{Spatial Data Verification and Validation}

In order to ensure the accuracy of the digitization process of the original maps, four quadrangles (approx. 12\%) were randomly chosen from the total list of 32 Quadrangles, and reproductions of those maps were produced on mylar using the digitized information. The sites on the original paper maps were compared with the digitized sites on the mylar maps for both point and polygon features. Out of the total number of sites that were checked, 332, there were no errors. The accuracy of the digitizing portion of the data entry was $100 \%$.

Also, as mentioned above, the RMS error was calculated for the registration of each original paper map that was digitized. Root Mean Square error is the measurement in inches of error that is calculated when the four corners of the paper map are registered to the TIC marks on the computer map. For example if the RMS error is .005 it means that the four comers of the digitized map are less than five hundredths of an inch off the original comers. The RMS errors were recorded for all 32 Quadrangles and ranged from .001 to .016 .

\subsection{Tabular Data Verification and Validation}

\subsubsection{Checking Key Values}

First, lists of site_identifiers were extracted from the Oracle database and from the Info database and trimmed to eliminate trailing blanks. Next the lists were merged using the 'cat' utility in UNIX. The resulting union of sets was sorted, and the 'uniq' UNIX utility was used to extract the complement of the intersected set. This complement was subsequently queried against the Oracle database to determine the records in the list that occurred uniquely in Oracle. Since the complement implied unique records from both databases, all of the records that did not match Oracle records were assumed to be uniquely Info records, and were written to file info_unique.lst.

At this point, the data were manually corrected in both systems to produce a discrete set of key values that matched in both Info and Oracle. As the data were being corrected however, sixty two Site_nuras were found in the Oracle database that did not show up in Info database. After checking each of the sixty two Site_nums manually on the data sheets and the original paper maps, it was determined that these sites in fact had not yet been mapped by the archeologist. The list of sites was recorded in a file called unmapped.sites. 


\subsubsection{Quality-Assuring Key Entry for Oracle}

A random number generator was used to produce a normally-distributed set of records in the range of 1 to 1500 . This set was about $5 \%$ of the total number of records, or 75. A view of the Oracle dataset was built consisting of record_number and site identifier. A SQL PLUS script was prepared to extract data from the dataset in the same order as the input records, and then the script file was modified to read the list of record numbers generated by the random number generator. The SQL PLUS script file named qa-rpt.lst, selected all records for a specified site from the Oracle tables which corresponded to the random record number generated.

The resulting list, verif.Ist, report was hand-compared to the original input records to determine the keystroke error percentage. The percentage was calculated by multiplying the total number of keystrokes per record (average of 20) by the number of records that were checked (75). This number (1500) was then divided into the total number of mistakes found (4) and then multiplied by 100 . The keystroke error percentage calculated out to be $.26 \%$. 


\section{ENGINEERED INTERFACE BETWEEN ARC/INFO AND ORACLE}

In order to speed up the process and enhance the accuracy of data entry, as well as, provide a means for non-GIS users (in this case Archeologists) to update and query data, an interface between ARC/INFO and Oracle was engineered. ARC/INFO provides the functionality to relationally join data in Database Management System (DBMS) tables to geographic features. The ARC/NFO tool, the Relational Database Integrator (RDBI), allows one or many Database Management Systems to be integrated, providing a generic interface to the attribute data stored in multiple databases. Storing data in a relational database allows concurrent multi-user access, independent user views and improved integrity management. In this application, Oracle was selected as the DBMS for integration with ARC/INFO. 


\section{ORACLE CONNECTIVITY}

A communication link between ARC/NFO and Oracle is required to use Database Integrator commands. In general, the ARC/NFO RELATE command, the CONNECT command, and DBMSEXECUTE or DBMSCURSOR commands are needed to make the relational database incerface with ARC/INFO. This section describes the links and relations necessary to connect to the Oracle database to access data from the DBMS.

\subsection{Oracle Relate Environment}

Both Oracle tables and INFO data files are related to a coverage's feature attribute table using a RELATE command. The RELATE command is used to relationally join the INFO file and the related Oracle table. The following example relates an INFO item to a column in the Oracle table.

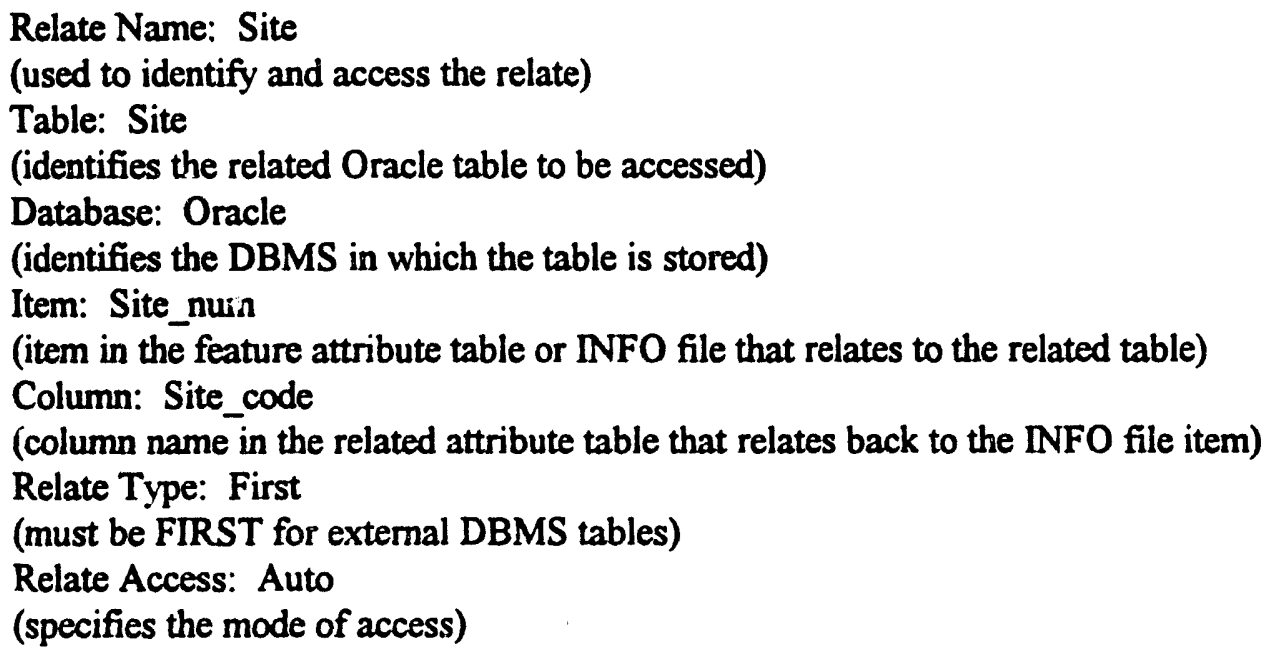

\subsection{Establishing an Oracle Connection}

The CONNECT command is used to log in to and access information in Oracle from ARC/INFO. A database definition file is required to provide specific login information for Oracle. The example below is a database definition file for connecting to Oracle.

Filename: Oracle.dbs

\subsection{Oracle DBI Server \\ \$ARCHOME/programs/oracle \\ @T:ERIS01:ERIS}

The first line in the file is a comment. The second line contains the operating system-specific path name to the server program to be used to establish connection between ARC/NNFO and Oracle. The third line is the address of the database server (T specifies TCPIP protocol, ERIS01 is the name of the computer, or node name, and ERIS is the SQL-standard name of the database).

The CONNECT command uses the database definition file described above. 
CONNECT Oracle /

(where Oracle is the Oracle.dbs file)

\subsection{DBMSCURSOR / DBMSEXECUTE Arc Commands}

The Database Integrator supports the query language native to Oracle using DBMSEXECUTE commands. Native SQL statements issued through the DBMSEXECUTE command can be used to manage data stored in Oracle from ARC/INFO. The following is an example of a select statement which will retrieve a selected set of records from the Oracle tables.

dbmsexecute oracle select site_code from site where site_code = 'BT555';

Native mode (Oracle) expressions can be used any time in ARC/INFO where a logical expression could be used. For example, in Arcedit, the following statement could be executed.

reselect archpoly poly ^site where site_code $=$ 'BT555'

The ^site represents the relation defined with the RELATE command, and the where clause is any valid Oracle select expression.

DBMSCURSOR commands allow access and modifications to the Oracle tables using cursor processing, from within Arcedit and Arcplot. A Cursor is a method for processing a selected set of records one row at a time. DBMSCURSOR commands do not use the relate environment. The following illustrates a cursor processing sequence.

Declare a cursor against a database with an SQL select expression.

Open the cursor.

Move through the rows in the cursor-selected set.

Update, delete, and inset rows in the Oracle tables.

Close the cursor.

Remove the cursor. 


\section{ARC MENU INTERFACE}

ARC/NNFO provides a graphic user interface using AML Menus. AML Menus provide a method to list operator selections on the screen, while form menus disp!sy the detailed information about the selected records. Cursor processing is used to display, update, or add data through a form menu interface. The data may be displayed as a scrolling list graphical widget, using buttons to navigate through the data.

\subsection{Forms and Menu Types}

ARC Menus are executed via the AML command \%MENU. A MENU may be a sidebar, matrix, or pull down type of display. These types of menus are used simply to select a choice from the screen and execute the command associated with the option. The following is an example of a sidebar Menu.

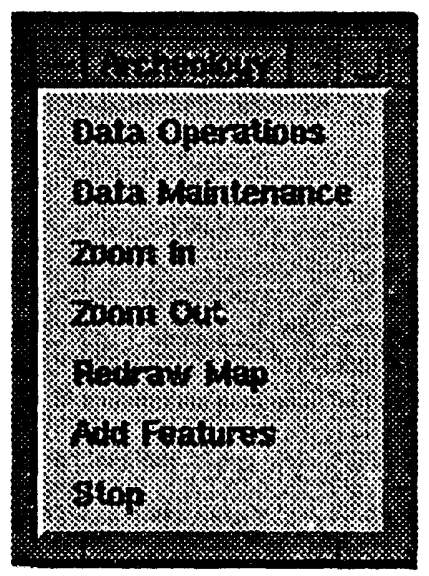

Form Menus should be used if user interaction is required. This type of menu allows the user to update and verify data input into the form, can provide list and pick pop-ups, set AML variables, and display the values of variables within the form. Below is an example of a form menu used to query information from the Oracle database. The form prompts the user to enter one or many site numbers by selecting the OR button and then DONE when completed. The CANCEL button allows the user to exit the form menu and return to the calling menu.

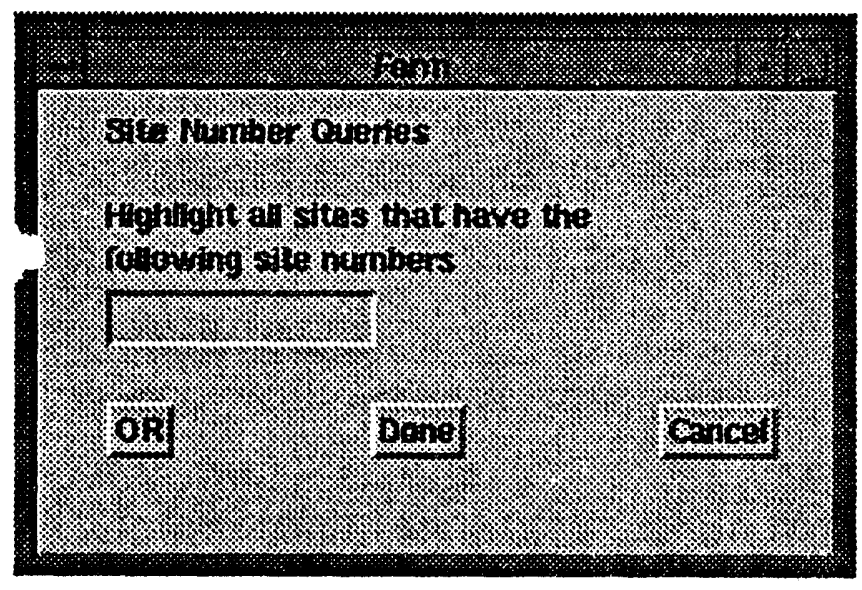


A form menu is the type of menu interface which allows direct data maintenance to the Oracle tables. DBMSCURSOR commands are used to construct, navigate, and modify tables of rows in memory as selected from the chosen database. The DBMSEXECUTE COMMIT command is used to store the changes in the Oracle database. The example below illustrates a data maintenance form menu.

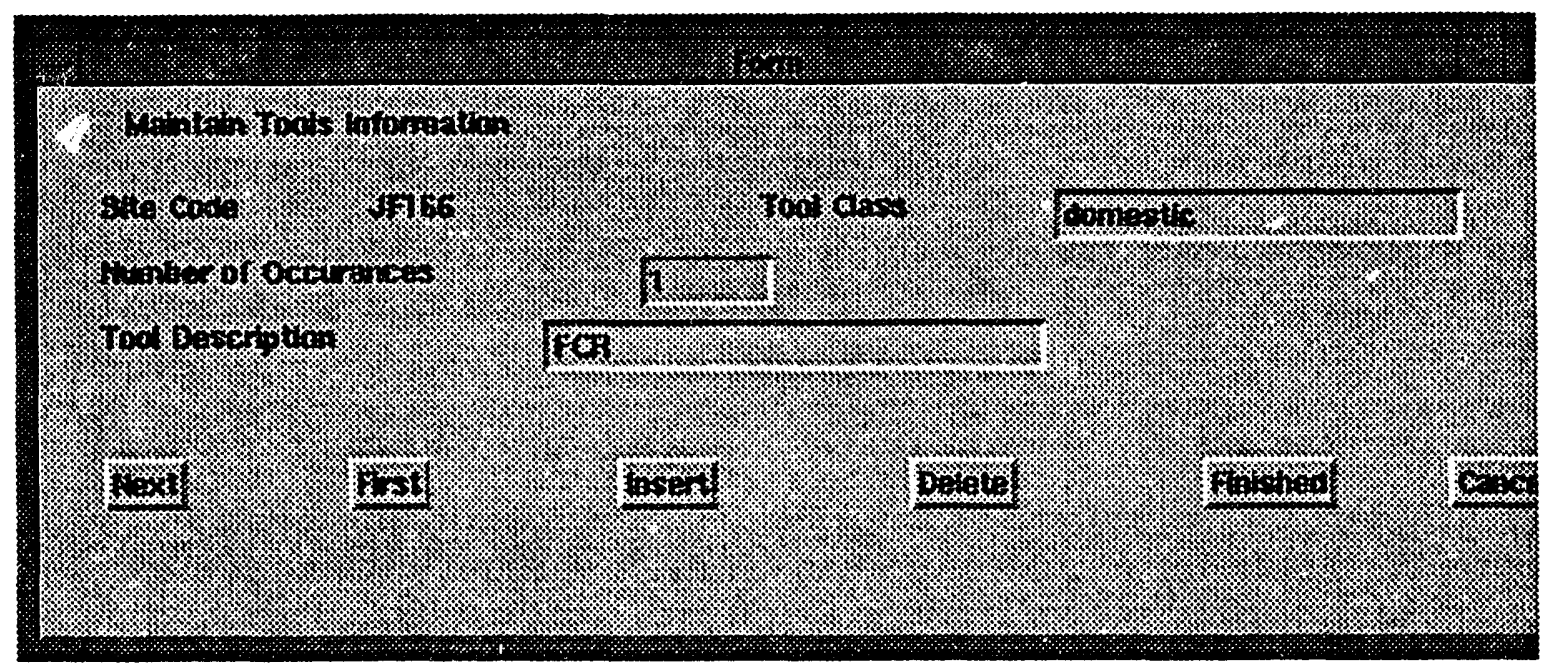




\section{APPENDIX A}

\section{ARCHEOLOGY DATA MAINTENANCE SYSTEM DESIGN}




\section{Appendix A \\ Archeology Data Maintenance System Design}

\section{A1.1 INTRODUCTION}

Over 1400 prehistoric cultural resources have been recorded on the Idaho National Engineering Laboratory during inventories required by the National Historic Preservation Act and National Environmental Policy Act. For the past ten years, the information collected from these sites has been recorded on paper. For purposes of geographically based predictive modeling and more affective overall management, archeologists at the INEL now have a need to query and analyze these data and to present the information graphically.

An Archeology Data Maintenance System will be implemented using ARC/INFO as the mapping tool , integrated with Oracle as the database management system. The system will allow the users to graphically represent data, query, update, or delete information from the Oracle database via an AML forms menu interface.

\section{A1.2 Archeology Database Design}

The following sections describe the data structure used for the Archeology Data Maintenance System. Figure A1.1 illustrates the entity relationship diagram for the Archeology Data Maintenance System. The relation Site stores information about the site itself and the historical or archeological remains found at the site. The relation Tool contains details about the tools found at the specified site. The relation Site_age consists of the age codes which represent the age of the site and the relation Cult_feature contains details about the cultural features associated with the site.

Section Al.3 is a data dictionary containing a brief description of each of the elements in the database. 
Archeology Data Maintenance System

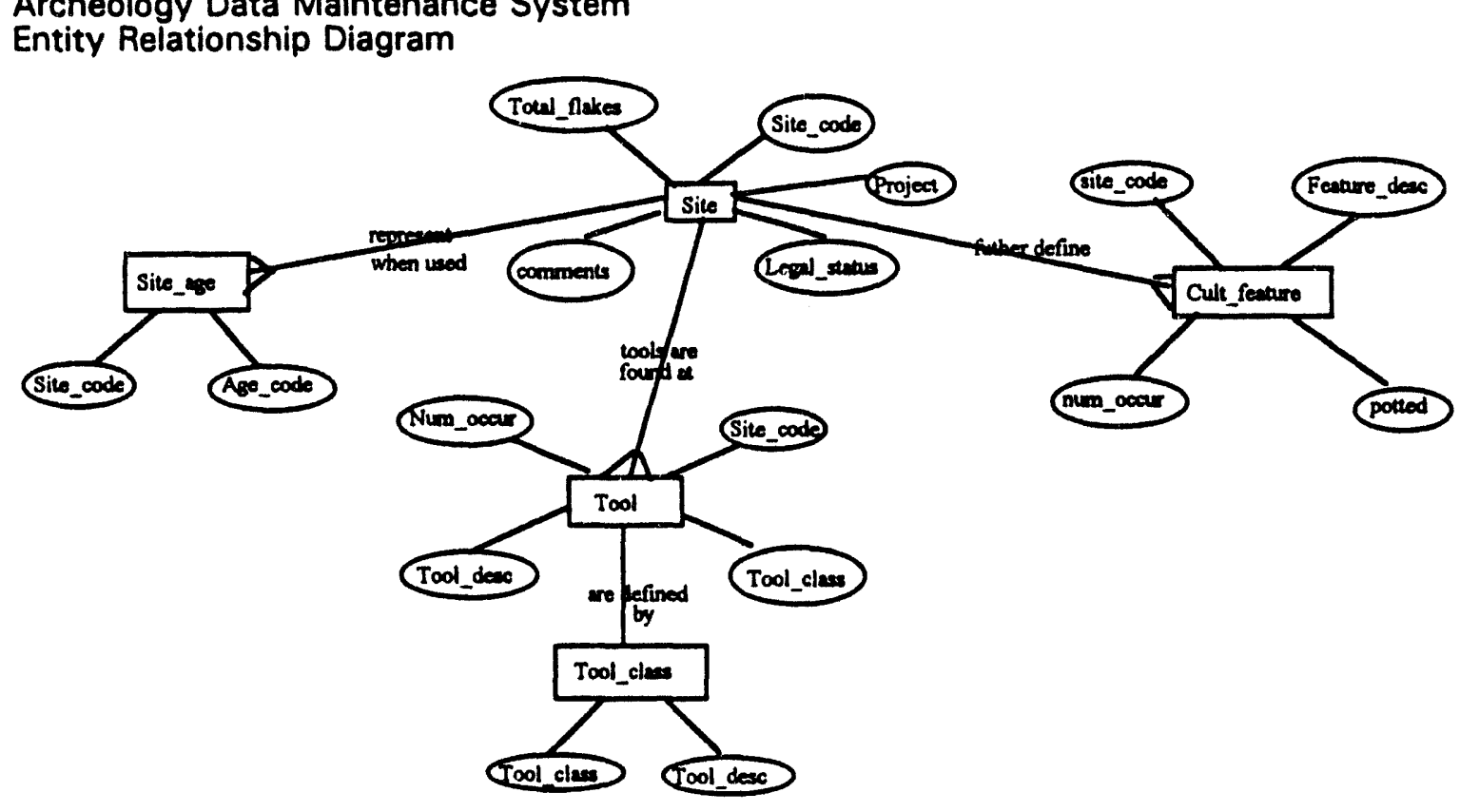

Figure A1.1 Entity Relationship Diagram

A3 


\section{A1.3 Data Dictionary}

Table Name: Site

Field Name: Site_code Field Type: Character Field Length: 12

Field Description: A site-specific unique identifier that represents the locus on the surface of the earth where archeological or historical remains are found.

Table Name: Site

Field Name: Project Field Type: Character Field Length: 20

Field Description: The identifier of the INEL project that funded the survey during which this particular field site location was recorded.

Table Name: Site

Field Name: Total_flakes Field Type: Number Field Length: 6

Field Description: An estimate of total surface detritus found at the site.

Table Name: Site

Field Name: Legal_status Field Type: Character $\quad$ Field Length: 3

Field Description: Potential for nomination to the National Register of Historic Places (i.e. signifigant=elgible, nonsignifigant=ineligible).

Table Name: Site

Field Name: Comments Field Type: Character Field Length: 60

Field Description: General purpose comments field for the referenced site.

Table Name: Tool

Field Name: Site_code Field Type: Character Field Length: 12

Field Description: The referenced site identifier as entered in the relation SITE.

Table Name: Tool

Field Nane: Tool_class Field Type: Character Field Length: 20

Field Description: The category of tool usage in which this particular referenced tool belongs.

Table Name: Tool

Field Name: Num_occur Field Type: Number Field Length: 6

Field Description: How many of these particular tools were found at the referenced site.

Table Name: Tool

Field Name: Tool_desc Field Type: Character Field Length: 25

Field Description: a text description of the tool as found.

Table Name: Tool_class

Field Name: Tool_class Field Type: Character Field Length: 20

Field Description: The category of tool usage (i.e.; procurement, processing, domestic, etc.). This corresponds to tool_class in the relation TOOL. 
Table Name: Tool_class

Field Name: Tool_desc

Field Type: Character

Field Length: 25

Field Description: A text description of the tool_class.

Table Name: Site_age

Field Name: Site_code

Field Type: Character

Field Length: 12

Field Description: The site code, as referenced in the relation SITE.

Table Name: Site_age

Field Name: Age_code

Field Type: Character

Field Length: 20

Field Description: Code representing the relative age of the site.

Table Name: Cult_feature

Field Name: Site_code Field Type: Character

Field Length: 12

Field Description: The site code that applies to this site, as referenced in the relation SITE.

Table Name: Cult_feature

Field Name: Feature_desc

Field Type: Character

Field Length: 20

Field Description: A description of any cultural features associated with this site. There may be many cultural features for a given site code.

Table Name: Cult_feature

Field Name: Num_occur

Field Type: Number

Field Length: 6

Field Description: How many of these particular cultural features are located at this site.

Table Name: Cult_feature

Field Name: Potted

Field Type: Character

Field Length: 1

Field Description: A Boolean indicating whether the site has been visited by non-archeologists, and artifacts have been removed. 


\section{A1.4 Archeology Data Access Interface Design}

The following three sections describe the forms menu interface to the Oracle database. Section A1.4.1 details the flow of the menus and their corresponding form menus. Section Al.4.2 explains the Database Maintenance portion of the system and contains layouts of the maintenance forms. The On-line Query form layouts are shown in section A1.4.3.

\section{A1.4.1 Forms and Menu System}

The Process Flow Diagram shown below illustrates the flow of the Archenlogy Data Maintenance System form menus and AMLs. The form menus are executed from calls in the AMLs (\%MENU). The process flow diagram lists the options available on each menu and the corresponding AML that invoked the form menu. The Archeology Data Maintenance System is started by executing the top level AML, ARCHDEMO.AML (\&r archdemu). A form menu is then displayed, showing the options available on the main menu. As options are selected from the main menu, corresponding lower level form menus and AMLs will be executed. 


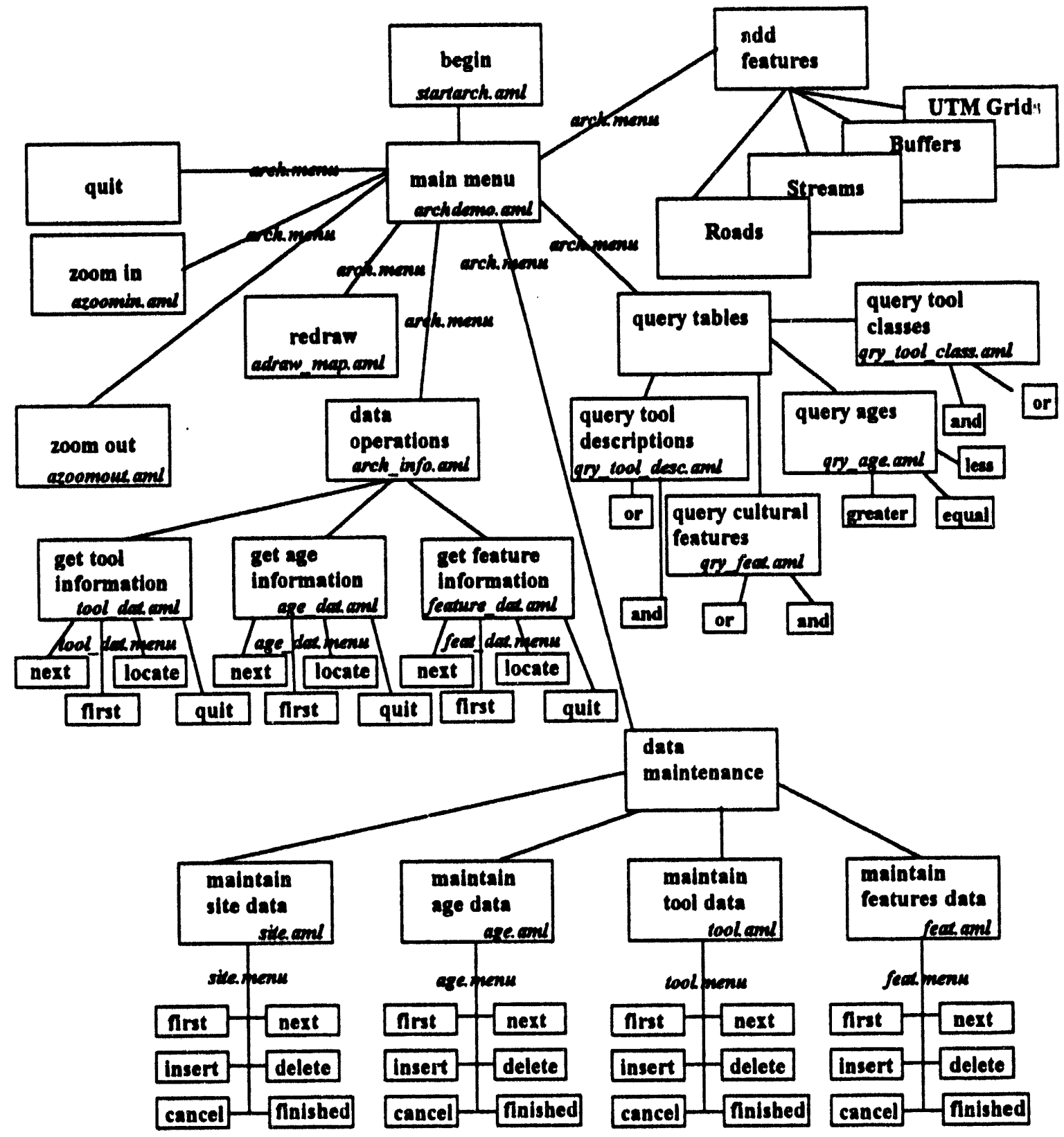

Figure A1.2 Archeology Data Maintenance System Process Flow Diagram 


\section{A1.4.2 Database Maintenanco System}

The recurds stored in the Site, Tool, Tool_desc, Site_age, and Cult_feature tables may be maintained in Oracle using form menus, DBMSCURSOR commands, and DBMSEXECUTE commands. Cursor processing is used to select a set of records and store them in memory for updates. All of the data maintenance forms will provide the ability to locate, insert, delete and modify the selected records by pressing the corresponding button on the form menu. A laysut of data maintenance forms is provided below.

The Archeology Data Maintenance System main menu is shown below. The maintenance submenu will appear by selecting the "Data Maintenance" option from the main menu. The maintenance forms will be used to add, modify, or delete records in the Oracle database. Any of these options allow the user to select the site on the map by clicking the mouse button on the desired point.

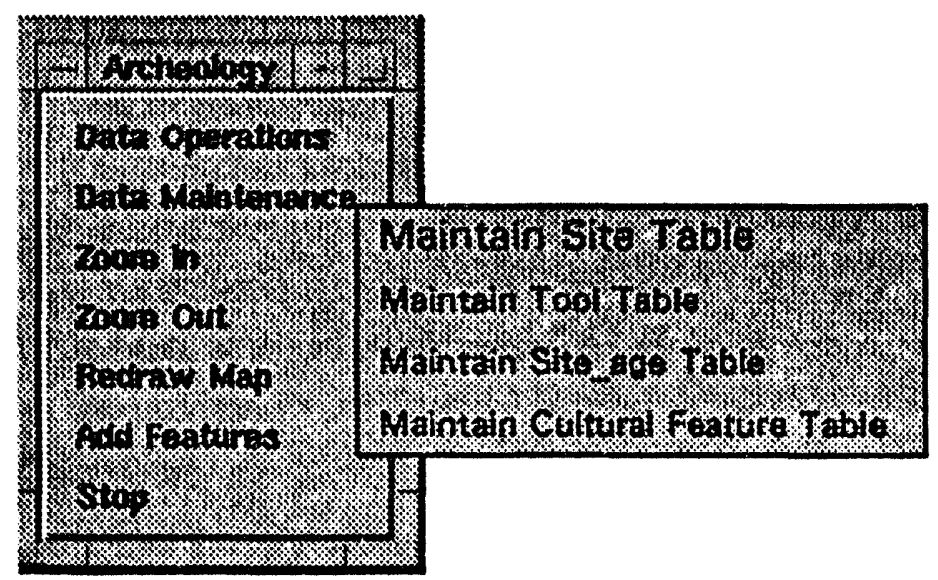

The Maintain Tool Information form is shown below. This form will be used to modify the Tool and Tool Description tables. The site code is not a modifiable field on this form. Tool class, number of occurrences and tool description may be modified. If several tool types exist for a specific site, the NEXT button can be used to scroll through the records. The FIRST button will return to first record stored in the selected set. The INSERT button will allow Tool class information to added., and DELETE will delete records from the Tool table. To commit the changes made to the record, the FINISHED button is used. CANCEL will cancel from the form menu without making updates to the database. 


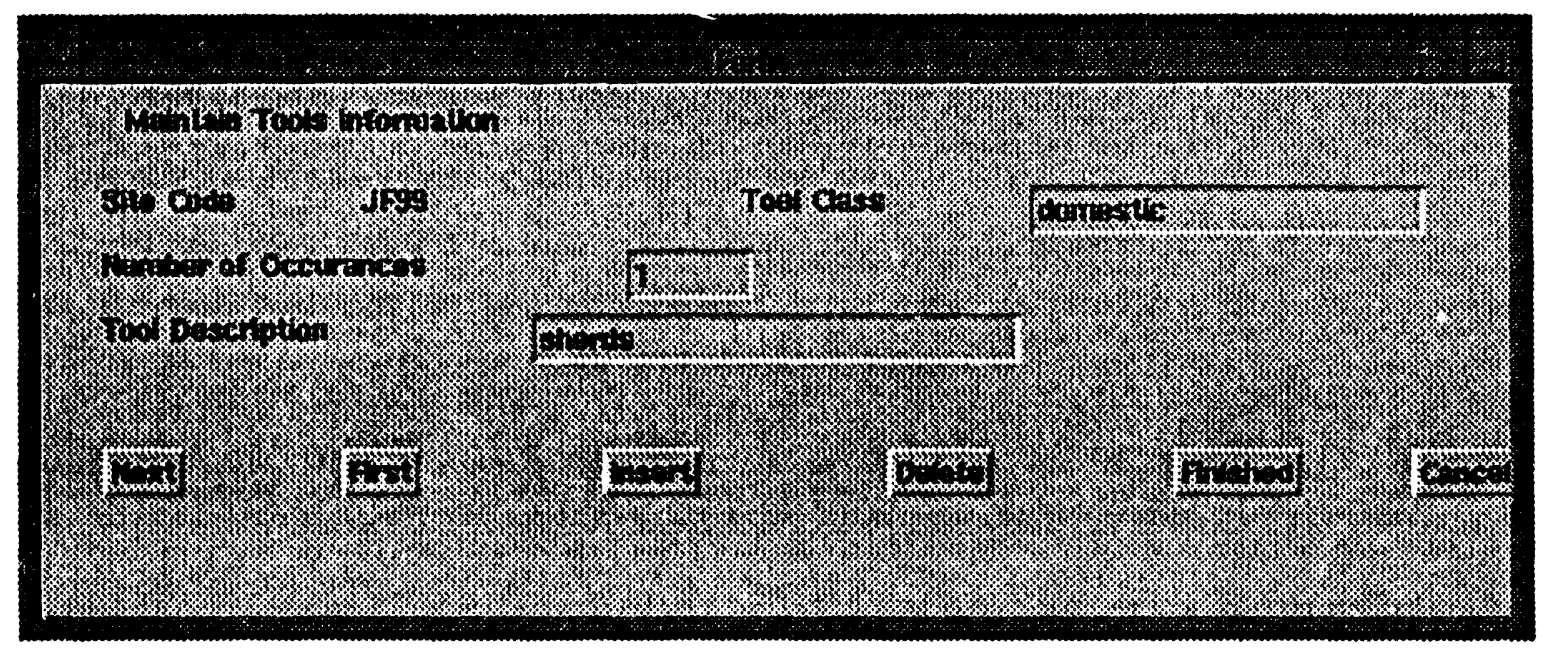

A layout of the Maintain Age Code Information is illustrated below. The form functions in exactly the same fashion as the above mentioned maintenance form. Only the Age_code in the Site_age table may modified, added, or deleted from the table.

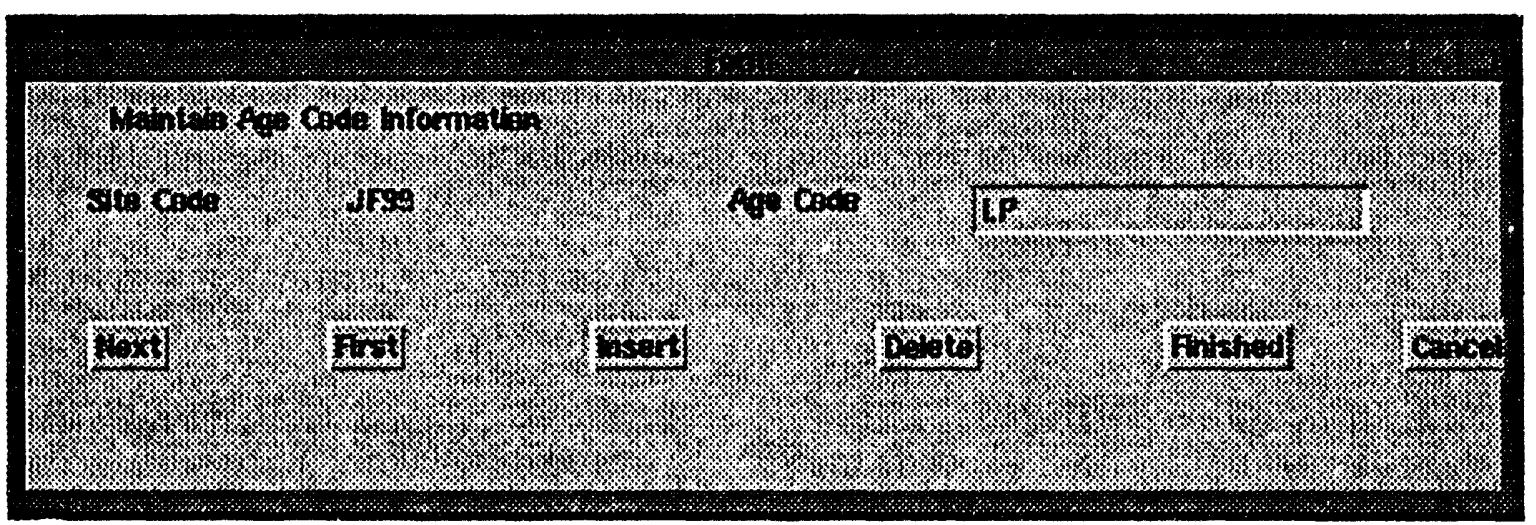

The Maintain Feature Information form shown below is used to manage cultural feature information for a specific site. Cultural Features and Number of Occurrences may be modified using this form. The Site number is not a modifiable field. If many cultural features exist for a site, the NEXT and FIRST buttons will be used to select the records. The FINISHED button will commit the updates to the database. 


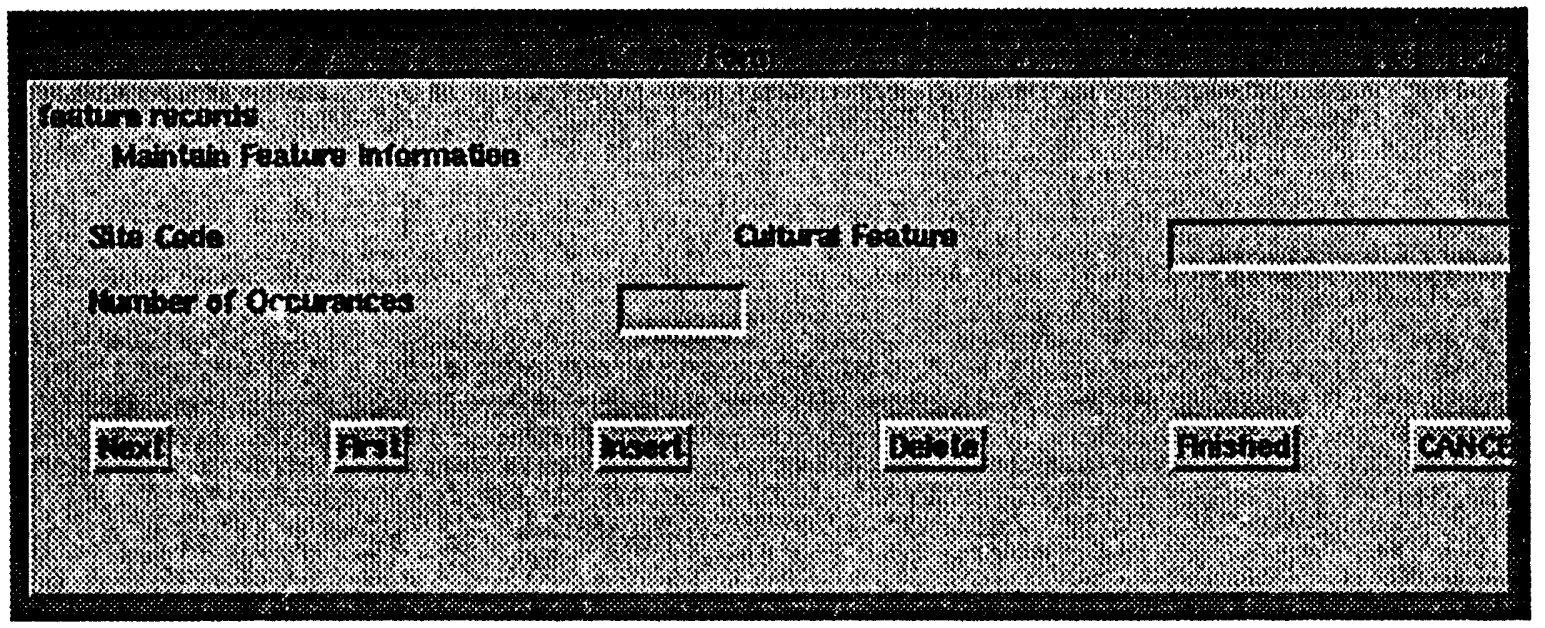

\section{A1.4.3 On-line Query System}

Information stored in the Oracle database may be queried by selecting the "Data Operations" option from the Archeology Data Maintenance System main menu. An additional sub-menu will appear with more detailed choices. The forms may be used to locate a site (or sites) on the map based on data stored in the Oracle database. Matches against the query will be represented on the map as Sites of different color. Subsequent forms will provide additional query refinement capabilities. Each query will reduce the selected set of records. The "Select All Sites" option will cancel the current set of selections and allow a new set of records to be queried.

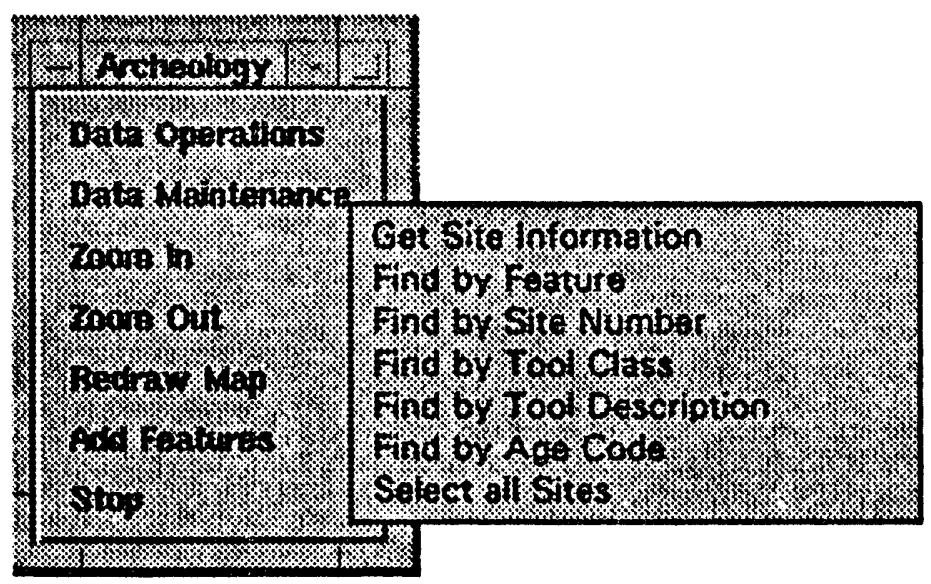

Selecting the "Get Site Information" option from the main menu will execute the following form. The form contains site specific irformation, the name, project, total flakes, legal status and comments. To view the tools found at a site, the TOOLS button is selected. The AGES button is used to list the age codes associated with the site, and FEATURES button will execute an additional form showing the cultural features associated with site. The FINISHED button will used to return back to the main menu. 


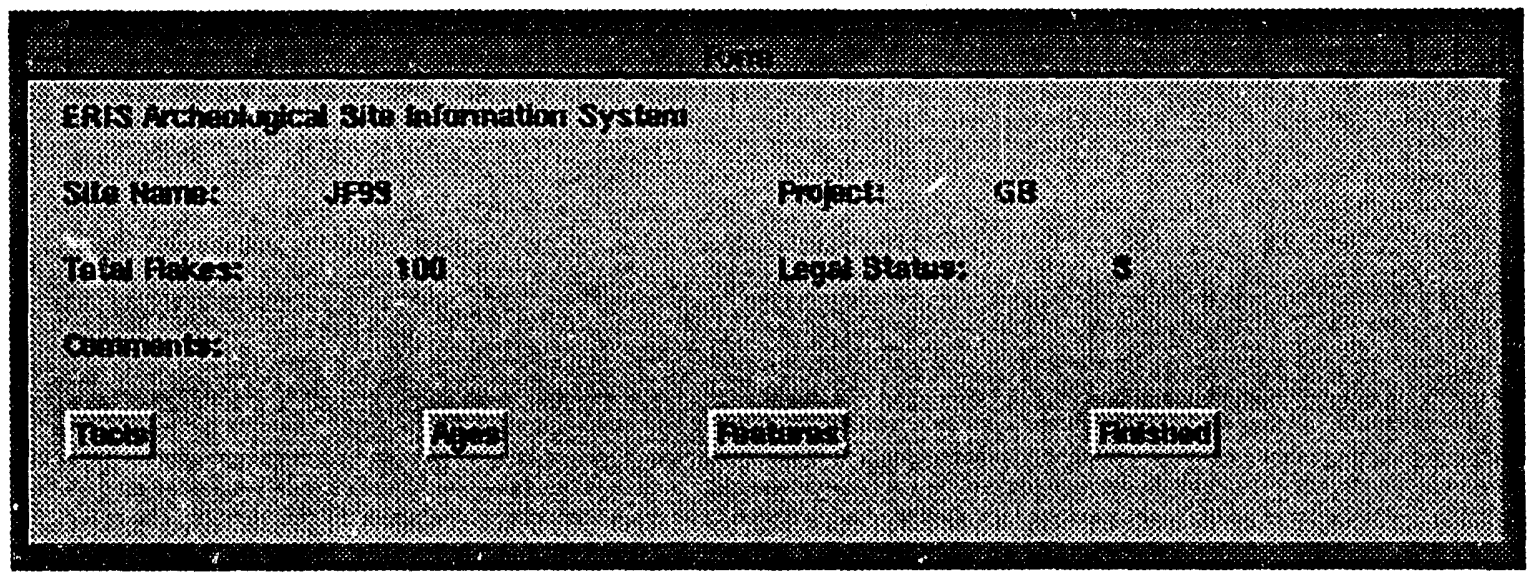

The form shown below is invoked by selecting the TOOLS button from the top level Site Information form. The form will provide the ability to scroll through the tools for a specific site by pressing the NEXT and FIRST buttons. FINISHED or CANCEL will return back to the Site information form.

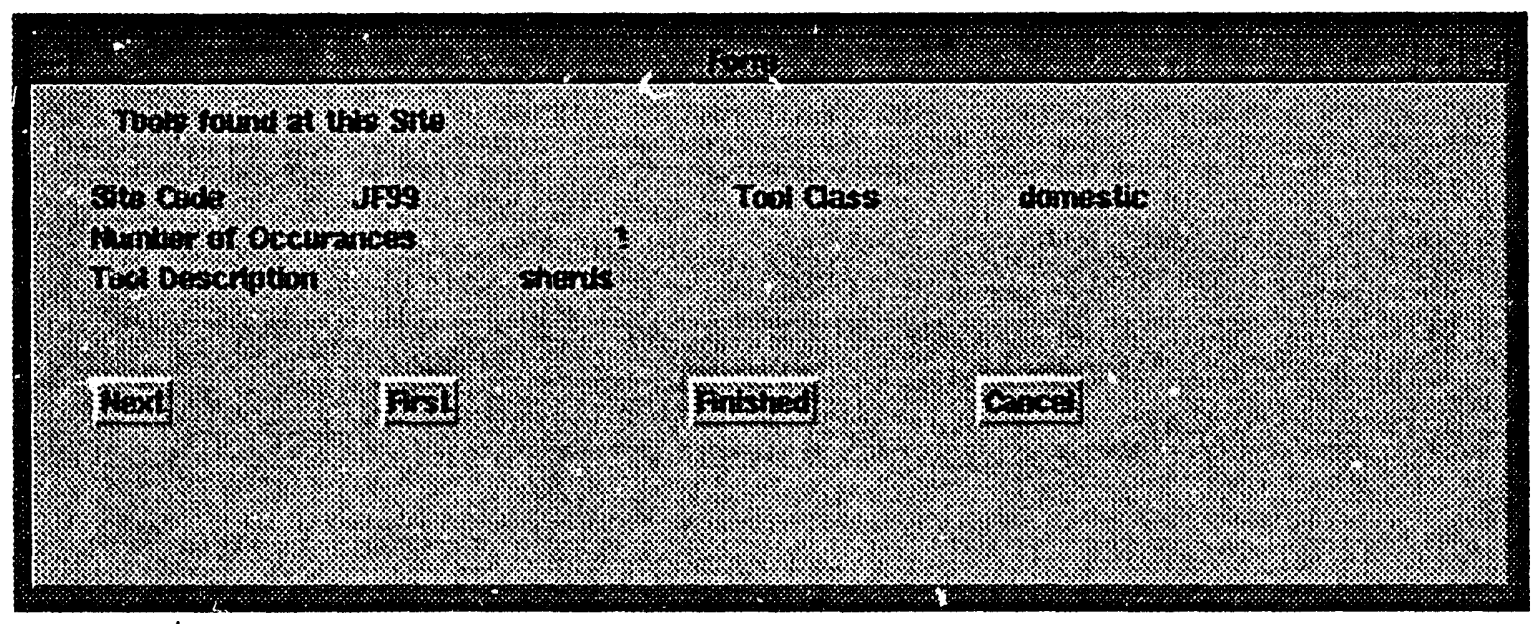

To view the age codes associared with a specific site, the AGES button from the site information form will be utilized. The form shown below represents the age code information for the site. Many age codes may exist for one site and can be viewed by selecting the NEXT and FIRST buttons. FINISHED and CANCEL will return back to the site information form. 

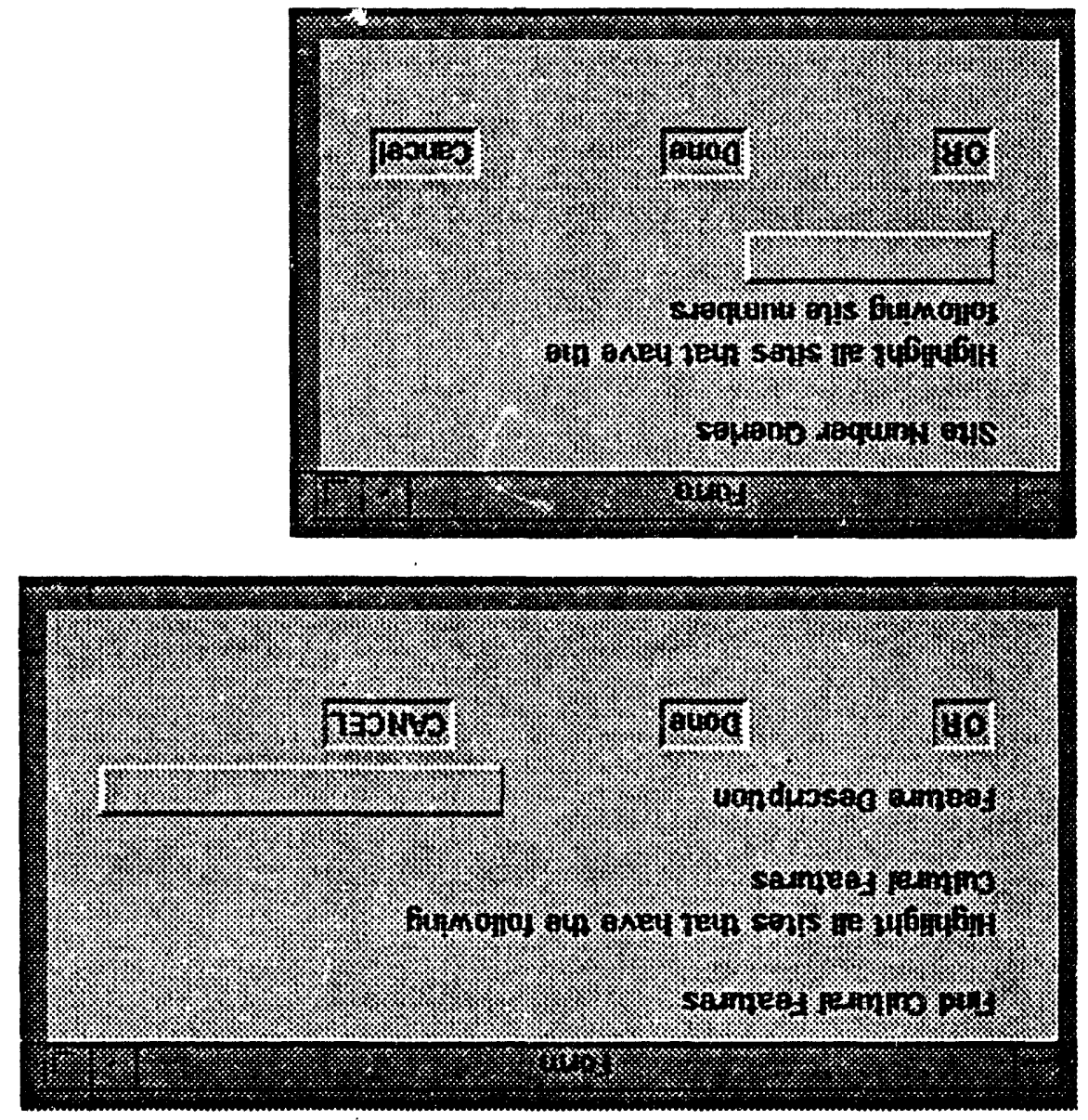

- joưrew

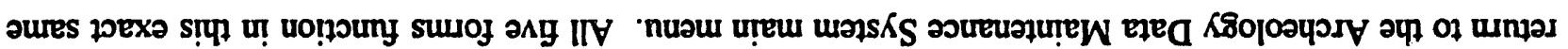

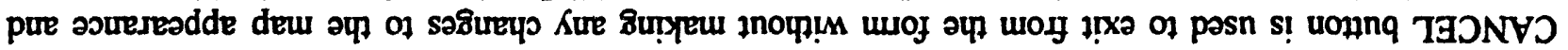

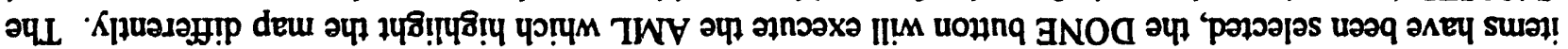

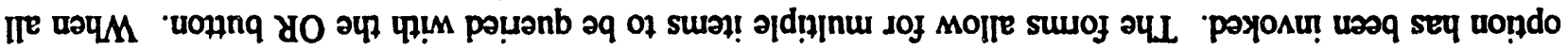

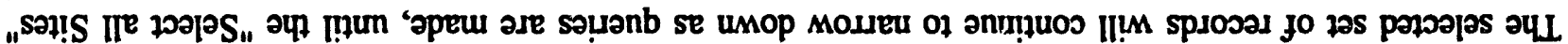

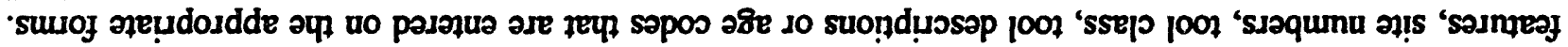

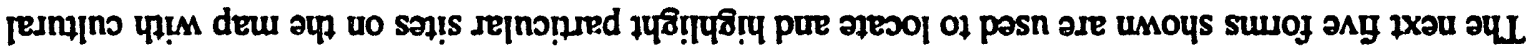

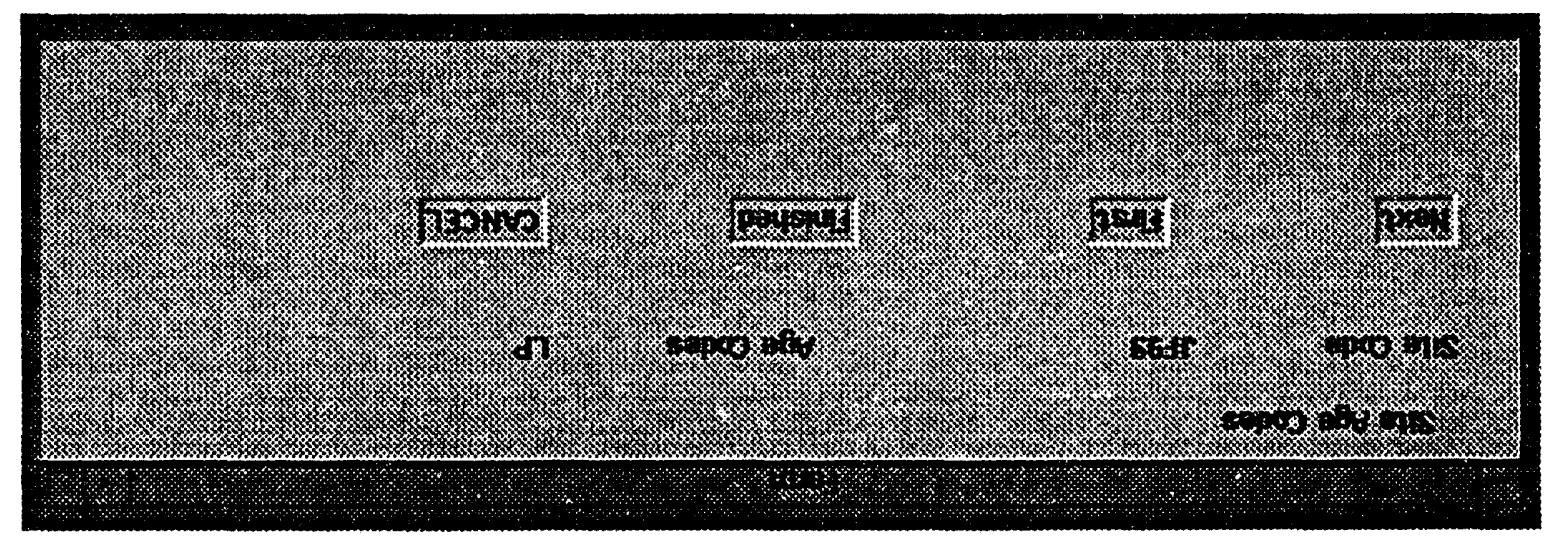



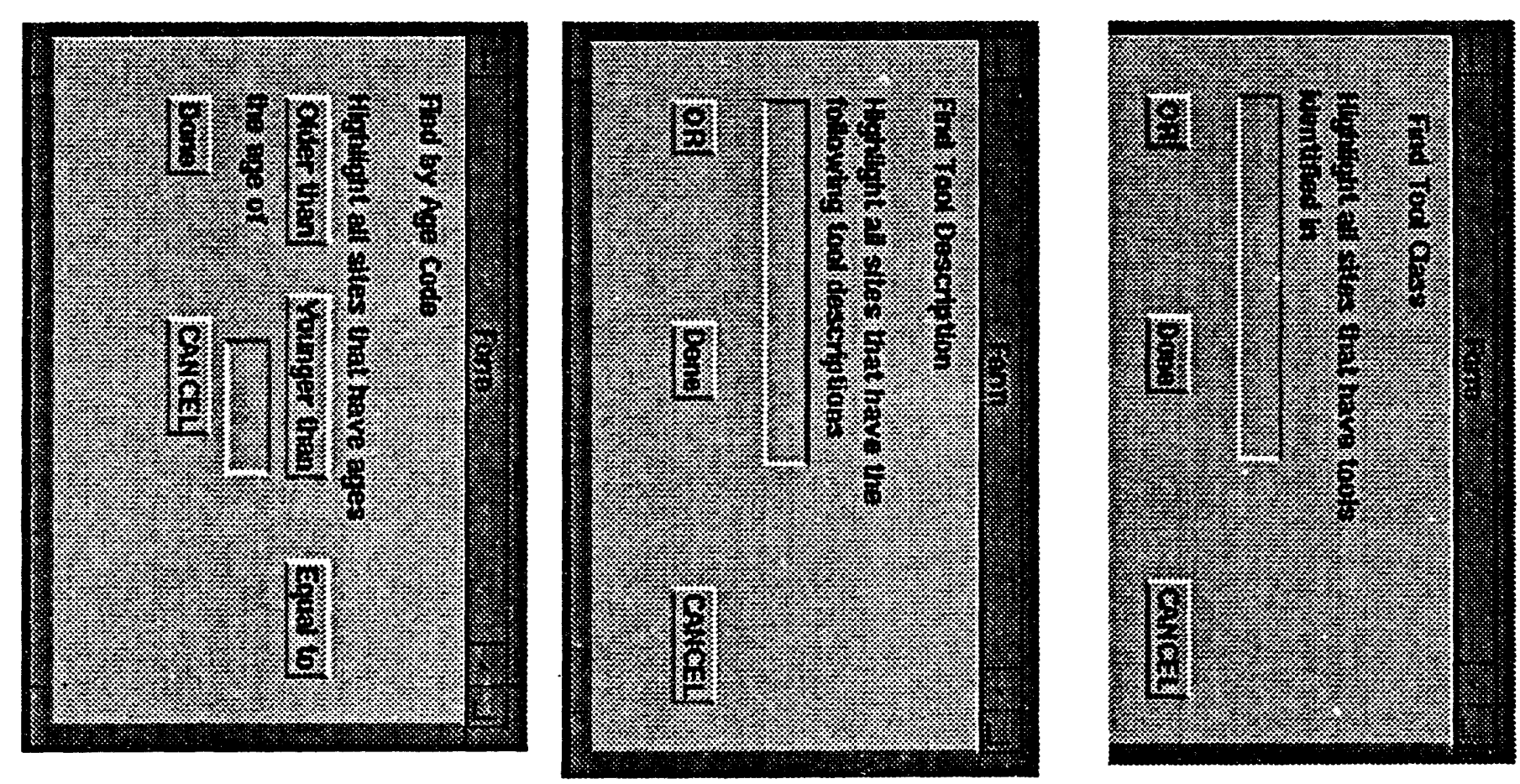

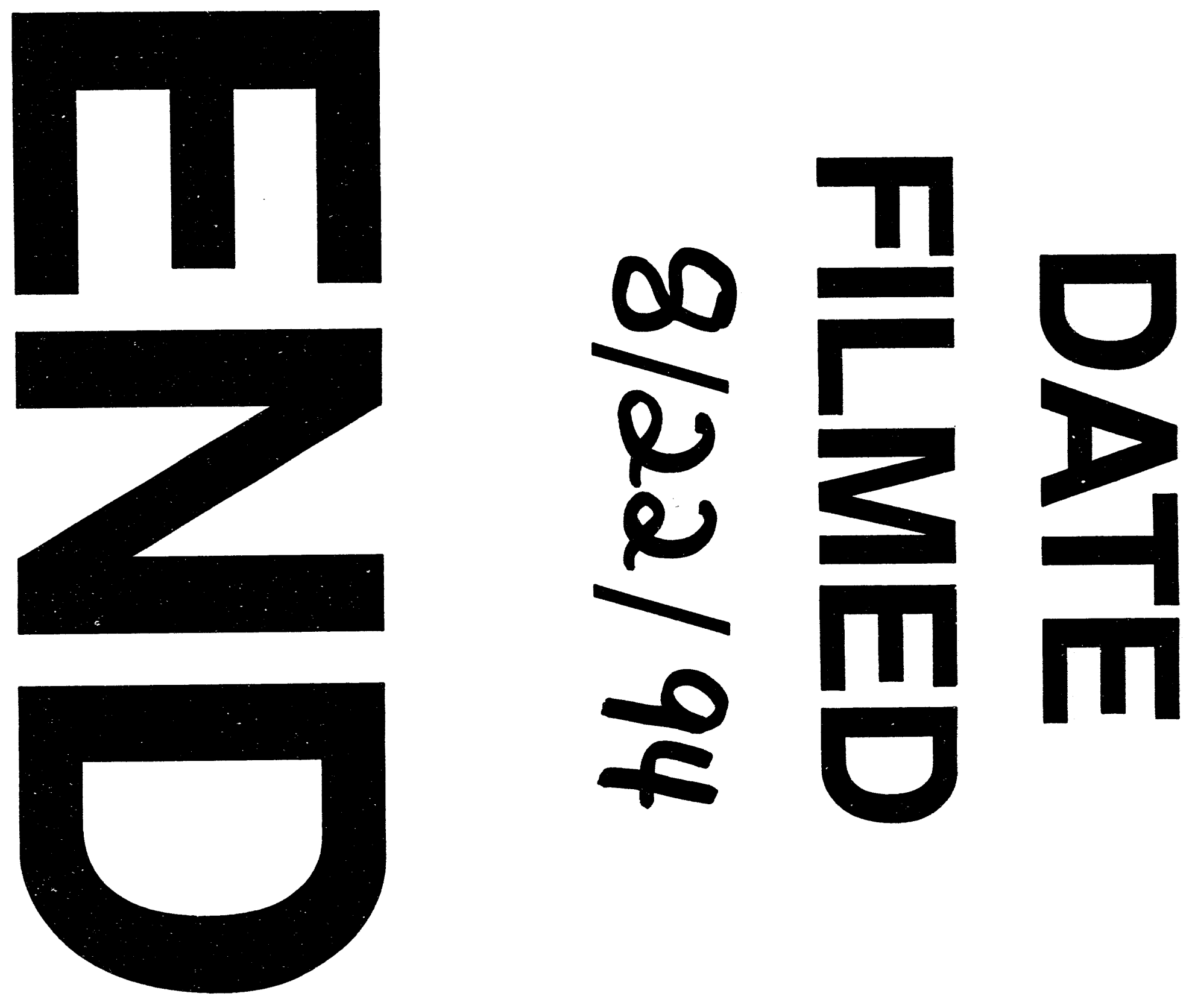
